2 Title: Postpartum maternal mental health is associated with cognitive

3 development of HIV-exposed infants in Zimbabwe: a cross-sectional study

4 Helen Mebrahtu1 (helen.mebrahtu.15@ucl.ac.uk); Dr Victoria Simms² (Victoria.Simms@LSHTM.ac.uk);

5 Rudo Chingono ${ }^{1,3}$ (rudo@ceshhar.co.zw); Zivai Mupambireyi ${ }^{3}$ (zietawana@yahoo.co.uk); Prof. Helen A.

6 Weiss $^{2}$ (Helen.Weiss@1shtm.ac.uk); Patience Ndlovu (pndlovu@zw.worlded.org); Ricky Malaba ${ }^{4}$

7 (rmalaba@zw.worlded.org); Prof. Frances M. Cowan ${ }^{3,5}$ (Frances.Cowan@1stmed.ac.uk); Prof. Lorraine

$8 \quad$ Sherr $^{1}$ (1.sherr@ucl.ac.uk).

9 8

${ }^{1}$ Department of Global Health, University College London, UK. ${ }^{2}$ MRC Tropical Epidemiology Group, London School of Hygiene and Tropical Medicine, UK. ${ }^{3}$ Centre for Sexual Health HIV/AIDS Research (CeSHHAR) Zimbabwe. ${ }^{4}$ World Education Inc./Bantwana (WEI/B), Zimbabwe. ${ }^{5}$ Department of International Public Health, Liverpool School of Tropical Medicine, UK.

Corresponding author: $\mathrm{H}$. Mebrahtu

Correspondence details: University College London, Department of Global Health, Royal Free Hospital Campus, Rowland Hill St, London, NW3 2PF.

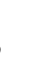
4 5 26 7 9 30 


\title{
Postpartum maternal mental health is associated with cognitive development of HIV-exposed infants in Zimbabwe: a cross-sectional study
}

\begin{abstract}
This study examines the cognitive profiles of infants born to HIV positive mothers in Zimbabwe.

Caregivers with HIV exposed infants delivered in 30 clinics in two areas of Zimbabwe were recruited to the study. Of the 574 study participants, 562 caregiver-infant dyads with a biological HIV+ve mother and infant aged 0-24 months were interviewed.
\end{abstract}

All infants were tested by a trained administrator for cognitive development on the Mullen Scales of Early Learning (MSEL). The Edinburgh Postnatal Depression Scale and Parental Stress Index-Short Form were completed by the mothers together with infant and caregiver socioeconomic characteristics. Linear regression models were used to relate cognitive development scores to maternal stress scores, maternal depression scores and infant HIV status adjusting for infant and caregiver characteristics, as well as socioeconomic factors.

Higher maternal depression scores were associated with lower overall infant cognitive scores (adjusted mean difference $(\mathrm{aMD})=-0.28$; CI 95\%:-0.50 to $-0.06 ; \mathrm{p}=0.01$ ) and in the expressive language ( $\mathrm{aMD}=-0.14$; $\mathrm{CI} 95 \%$ :-0.27 to $-0.01 ; \mathrm{p}=0.04)$, fine motor skills ( $\mathrm{aMD}=-0.17$; $\mathrm{CI} 95 \%$ : 0.33 to $-0.01 ; \mathrm{p}=0.03$ ), gross motor $(\mathrm{aMD}=-0.22 ; \mathrm{CI} 95 \%:-0.40$ to $-0.04 ; \mathrm{p}=0.02)$, and visual reception $(\mathrm{aMD}=-0.22$; $\mathrm{CI} 95 \%:-0.40$ to $-0.05 ; \mathrm{p}=0.01)$ domains. Higher maternal stress was associated with poorer overall infant cognitive scores ( $\mathrm{aMD}=-0.11 ; \mathrm{CI} 95 \%:-0.20$ to $-0.02 ; \mathrm{p}=0.02$ ) and in the specific domains of expressive language ( $\mathrm{aMD}=-0.07$; CI 95\%:-0.12 to $-0.01 ; \mathrm{p}=0.01$ ), gross motor skills ( $\mathrm{aMD}=-0.12$; $\mathrm{CI} 95 \%:-0.18$ to $-0.05 ; \mathrm{p}<0.01)$ and visual reception $(\mathrm{aMD}=-0.09$; CI 95\%:-0.16 to -0.02; $\mathrm{p}=0.02$ ). Comparisons between the small number of HIV positive infants $(n=16)$ and the HEU infants $(n=381)$ showed the latter to have higher mean gross motor scores ( 50.3 vs. $40.6 ; \mathrm{p}=0.01$ ). There was no evidence of difference by HIV status in the other MSEL domains or overall mean cognitive scores.

Our findings demonstrate the association between maternal mood and stress levels and child cognitive functioning, particularly in expressive language and visual reception development. Although cross sectional data cannot shed light on the direction of this association, the study suggests that interventions to address maternal stress and depression symptoms may prove to be beneficial.

Word count: 337 
Key words: Maternal mental health; Cognitive development; HIV infected and exposed infants; Mullen scales of early learning; Sub-Saharan Africa

\section{Introduction}

Although the burden of HIV/AIDS in children is steadily decreasing, an estimated 2.1 million ( $<15$ years) children worldwide are living with HIV (UNAIDS, 2017). The majority (81\%) of new paediatric HIV infections are recorded in children living in Africa (UNAIDS, 2015). There is substantial evidence documenting the negative impacts of HIV on child development outcomes, particularly cognitive development.

Multiple studies examining the effects of HIV infection and exposure (without becoming infected) on children's cognitive development have described the risk of developmental delay and impairment in both HIV infected and HIV-exposed uninfected infants (HEU) (Blanchette, Smith, FernandesPenney, King, \& Read, 2001; Gay et al., 1995; Hutchings \& Potterton, 2013; Knight, Mellins, Levenson, Arpadi, \& Kairam, 2000) compared to healthy control infants (Van Rie, Mupuala, \& Dow, 2008), particularly in resource-limited settings (Le Doare, Bland, \& Newell, 2012; Sherr, Croome, Parra Castaneda, Bradshaw, \& Herrero Romero, 2014; Smith et al., 2012). Furthermore, perinatally-infected children face greater risk of neurological and neuropsychological deficits compared to HEU infants. This may be due to direct effects of HIV on the central nervous system and the brain structures involved in the regulation of emotion, behaviour, and cognition (Albright, Soldan, \& Gonzalez-Scarano, 2003; Blanchette et al., 2001; Epstein \& Gelbard, 1999; Gay et al., 1995; Revicki, Chan, \& Gevirtz, 1998), exposure to treatment or other HIV related factors. HIV can also impact the neurodevelopment of children indirectly through its negative influences on the child's living environment (Van Rie et al., 2008), including poverty, food insufficiency, community stigma and discrimination, caregiver unemployment, caregiver illness and bereavement (Lowick, Sawry, \& Meyers, 2012; L. Richter, 2004; L. M. Richter et al., 2009; Sherr et al., 2014; Walker et al., 2007). The developmental outcomes of children affected by HIV are further influenced by other factors, including the extent of early years stimulation, and maternal mental health (GranthamMcGregor et al., 2007; Murphy, Marelich, Armistead, Herbeck, \& Payne, 2010). Research suggests that quality of caregiving provided to HIV positive and affected children plays a role in mitigating these negative outcomes (Bass et al., 2016).

Current literature has established that maternal stress and anxiety are negatively associated with child developmental outcomes (Murphy et al., 2010; Murray et al., 2017) in the general population and affect a broad range of parenting skills, which are negatively associated with poorer parentchild communication, poorer and less consistent parenting discipline leading to child problem 

behaviours (Murphy et al., 2010). Exposure to maternal depression in particular has a negative influence on child development in infancy and early childhood, and is associated with impaired cognitive performance leading to social, behavioural problems and compromised physical health (Black et al., 2007; Comaskey et al., 2017; Cummings \& Davies, 1994; LeWinn et al., 2009). A South African study found that maternal depression was related to increased parenting stress and parent-child dysfunction which was again associated with children's behaviour and functioning (Allen et al., 2014).

Understanding the role of HIV and maternal mental health in child development is critical. A study has shown that living with HIV and caring for AIDS orphaned children increased the odds of clinically relevant anxiety symptoms among South African caregivers (Kuo, Cluver, Casale, \& Lane, 2014). It is understandable that maternal stress is exacerbated when living with a chronic condition such as HIV, where caregiving duties and coping with psychological and medical demands of dealing with life-threatening condition are difficult (Murphy et al., 2010). However, there is a circular pattern observed between parenting stress and children dysfunctional behaviour, where parenting stress and children's behavioural problems exacerbate one another.

The relationship of maternal mental health and cognitive functioning of children needs further exploring, with a need for studies in other Sub-Saharan African countries. This study aimed to investigate cognitive differences in children infected and affected by HIV and the relationship between maternal stress and depression scores, and child cognitive performance in Zimbabwe.

\section{Study Design}

This is a cross-sectional analysis of baseline data collected as part of a cluster-randomized controlled trial (The Child Health Initiative for Developmental Outcomes [PACTR201701001387209]) prior to implementation of the intervention. Participants were recruited from catchment areas surrounding 30 clinics in 2 rural districts of Zimbabwe.

\section{Participants}

All mothers with confirmed HIV status during pregnancy were recruited to the trial, via the Exposed Infant Registers, held at clinics. For infants to be eligible for inclusion, they had to be singleton births, aged 0 to 24 months, and not suffering from other chronic illness (not including HIV).

\section{Enrolment Procedures}


Eligible participants were invited to attend an orientation meeting to learn about the trial. After orientation, eligible caregivers who provided verbal consent to enrol were booked for enrolment procedures and baseline assessments. At enrolment, a questionnaire was administered to participating caregivers by a trained interviewer with more sensitive information being collected using audio computer-assisted survey instrument (Langhaug et al., 2011).

Two trained nurses who were blind to the infant's HIV status carried out the developmental assessments using the Mullen Scales of Early Learning (MSEL). Data on the developmental assessment of the infants were collected and double-entered onto a specialized database by the research team. The developmental assessment procedures of the infants were video recorded and randomly selected sessions were reviewed to assess reliability and repeatability of assessments.

\section{Assessment Measures}

\section{i) Infant cognitive measure}

The cognitive profiles of the participating infants were assessed using the MSEL. The MSEL is based on the theory that a child's intelligence is most accurately conceptualized as a network of interrelated but functionally distinct cognitive skills (Boivin, Nakasujja, Sikorskii, Opoka, \& Giordani, 2016; Mullen, 1995). It is an individually administered comprehensive measure that assesses a child's abilities in visual, linguistic, and motor domains, and distinguishes between receptive and expressive processing for infants and preschool children from birth through 68 months. The five domains assessed here were gross motor skills, visual reception, fine motor skills, receptive language, and expressive language (Mullen, 1995). The MSEL was administered to all infants in the standardized format upon enrolment in the study. The infant's primary caregiver was sat in a chair behind the child if the child was able to sit at a chid sized testing table, or with the caregiver depending on age.

The test scores obtained by the children for each MSEL scale were transformed into an agestandardized T-score, using a US reference population as there is no local Zimbabwean reference population on this index. The standardized T-scores of four components - the fine motor, expressive language, receptive language, and visual perception scales were combined to produce the Early Learning Composite (ELC) score. Composite scores were used in this analysis to measure general cognitive functioning. Gross motor scale was not included in the ELC score and was used separately as an indicator concentrating on their motor skills (Akshoomoff, 2006; Mullen, 1995).

\section{ii) Maternal mental health measure}

The Edinburgh Postnatal Depression Scale (EPDS), a postpartum depression-screening questionnaire that has been validated for use in Zimbabwe (Chibanda et al., 2010; Cox, Holden, \& 
Sagovsky, 1987) was administered to participating mothers. The EPDS comprises 10 questions which generate scores ranging from $0-30$. The literature provides a cut-off point $(\geq 12)$ indicating concerns for referral. These cut-off levels used in past research in similar settings found that this threshold was effective in detecting woman with major, and minor depression with sensitivity of 80\% (Gibson, McKenzie-McHarg, Shakespeare, Price, \& Gray, 2009). The EPDS scores allow for a categorisation into none or minimal (EPDS scores 0-6), mild (EPDS scores 7-13), moderate (EPDS scores 14-19) and severe depression (EPDS scores 20-30) (McCabe-Beane, Segre, Perkhounkova, Stuart, \& O'Hara, 2016). The EPDS is not diagnostic.

Parental Stress Index-Short Form (PSI-SF), a self-completed screening tool used for identifying different types of stress associated with parenting, was administered to caregivers (Abidin, 1995). This index comprises of 3 subscales: Parental Distress, Parent-Child Dysfunctional Interaction and Difficult Child. Child and Parent domains combine to form Total Stress Score. These are scored using the following 5-point scales: (strongly agree, agree, not sure, disagree, and strongly disagree) and generate scores ranging from 40-149.

\section{iii) Socioeconomic measure}

Hunger has consistently emerged to be a major concern among Sub-Saharan African populations living with HIV (Murray et al., 2017), hence a subset of questions from the Household Food Insecurity Access Scale (Coates, Swindale, \& Bilinsky, 2007) were used to assess household food security. These were used to categorise participants as living in: i) food secure (rarely worried about food access or quality), ii) moderately food insecure (sometimes i.e. 3-10 times in the last month, worried about food access or quality), or iii) severely food insecure households ( $\geq 1$ household member going to bed hungry or often worrying about food access or quality).

Other sociodemographic information such as: infant characteristics (age, gender, birth weight, growth rate-obtained from child's health card), caregiver characteristics (age, marital status) and socioeconomic factors (educational level, employment status, and number of adults living in the household) were also collected.

\section{Statistical Analysis}

Infant and caregiver characteristics as well as socioeconomic factors were described using mean and standard deviations (SD) for continuous variables, and frequency percentages for categorical variables. Only biological mothers (i.e. excluding other type of caregivers) were included in this analysis. The MSEL scores were reported using mean, SD, and adjusted mean differences $(95 \% \mathrm{CI})$. Prior to data analysis, score distributions on all dependent measures were examined to test the assumptions of normality and homogeneity of variance. In addition, data were 
adjusted for clustering by clinic. All analyses were performed using STATA v.14.1 (StataCorp LP, College Station, Texas, USA).

\section{i) Maternal stress and mood and cognitive development of infants}

Linear regression models were fitted to relate MSEL scores to exposure variables maternal stress (using PSI-SF), and mental health (using EPDS) respectively. EPDS and PSI-SF total stress scores were tested against the MSEL scales both univariably and adjusting for confounders. HIV status was included in the models a priori. Results were reported using mean EPDS scores, mean total stress scores, SD, unadjusted and adjusted mean differences.

\section{ii) HIV status and cognitive development of infants}

For this analysis infants with unknown HIV status were excluded. Infant HIV status was established by caregiver report and/or clinic records at enrolment or baseline assessment. HEU infants were defined as having confirmed HIV negative status but born to an HIV infected biological mother. Student's t-test and Pearson's chi square were used to test for differences in selected demographic infant and caregiver characteristics by HIV status.

Univariate models were used to assess the relationship between MSEL scores and the infant's HIV status, and multivariate regression was then used adjusting for potential confounders - i.e. variables that were associated with both the outcome and the exposure $(p<0.2)$. Infant's age and gender were included in the models a priori.

\section{Ethical Approval}

The trial has been approved by the Medical Research Council of Zimbabwe (MRCZ/A/1943), University College London (6789/002) and the London School of Hygiene and Tropical Medicine (9912).

\section{Results}

Of the 671 eligible caregiver-infant dyads invited to participate in the trial, 574 (86\%) agreed to do so. The caregivers sample included 562 (98\%) biological mothers and $12(2 \%)$ other caregiversmainly grandmothers. Data from the biological mothers only were included for analysis. For the HIV status and infant cognitive development models, infants with unknown HIV status were further excluded ( $\mathrm{n}=165)$, leaving a total of 397 dyads.

\section{Maternal stress and mood}


Infant and caregiver characteristics are summarized in Table 1. The mean age of infants was 11.9 (SD 6.5) months, and 51\% were girls. The mean age of mothers was 32 years (SD 6.3). Over half (54\%) of mothers had completed secondary school level education and $37 \%$ were in paid employment. Most households (91\%) had 1-3 resident adults, and two in five (40\%) households suffered from food insecurity i.e. members worried about food access or at least one family member went to bed hungry. The mean maternal depression score on the EPDS scale was 11.5 (SD 6.5). When using the EPDS cut-off scores for mild, moderate and severe depression, over half (64\%) of mothers experienced mild or moderate depression, with 10\% categorised as having severe depression. The mean maternal stress score on the PSI SF scale was 84.8 (SD 16.3).

Results from multivariate models suggest that maternal stress and depression scores were associated with the infants' cognitive scores. Higher maternal EPDS depression scores were associated with lower infant cognitive scores in the early learning composite score (adjusted mean difference $(\mathrm{aMD})=-0.28$; CI 95\%: -0.50 to $-0.06 ; \mathrm{p}=0.01)$ and all domains; expressive language $(\mathrm{aMD}=-0.14$; CI 95\%: -0.27 to $-0.01 ; \mathrm{p}=0.04$ ), fine motor skills ( $\mathrm{aMD}=-0.17$; CI 95\%: -0.33 to $-0.01 ; \mathrm{p}=0.03$ ), gross motor ( $\mathrm{aMD}=-0.22$; CI 95\%: -0.40 to $-0.04 ; \mathrm{p}=0.02$ ), visual reception ( $\mathrm{aMD}=-0.22$; $\mathrm{CI} 95 \%$ : 0.40 to $-0.05 ; \mathrm{p}=0.01$ ), and weakly associated with receptive language $(\mathrm{aMD}=-0.15 ; \mathrm{CI} 95 \%$ : -0.30 to $0.01 ; \mathrm{p}=0.07$ ) (Table 2). Infant's age, and caregiver's employment status, were found to negatively influence the relationship between maternal depression scores and MSEL scores.

Similarly, maternal stress scores were associated with infant cognitive scores (Table 3). Higher stress scores were associated with poorer infant scores in the early learning composite score $(\mathrm{aMD}=-0.11$; CI 95\%: -0.20 to $-0.02 ; \mathrm{p}=0.02)$ and in expressive language (aMD=-0.07; CI 95\%: 0.12 to $-0.01 ; \mathrm{p}=0.01$ ), gross motor skills ( $\mathrm{aMD}=-0.12$; CI $95 \%$ : -0.18 to $-0.05 ; \mathrm{p}<0.01$ ), visual reception ( $\mathrm{aMD}=-0.09$; CI 95\%: -0.16 to $-0.02 ; \mathrm{p}=0.02$ ), and weakly associated with receptive language ( $\mathrm{aMD}=-0.06$; $\mathrm{CI} 95 \%$ : -0.13 to $0.00 ; \mathrm{p}=0.06$ ). Infant's age, growth rate, and examiner to administer MSEL were found to be confounders in the relationship between maternal stress scores (PSI-SF total stress) and MSEL scores.

\section{Infant HIV Status}

From a total of 397, there were 16 HIV positive infants and 381 HEU infants. HIV status was not associated with infant's age at enrolment, gender, or birth weight (Table 4). However, the mothers of HEU infants were slightly older than HIV positive infants mothers (32 vs. 29; $p=0.05$ ). Mothers caring for HIV positive infants reported higher mean stress scores compared to the HEU group (95.8 vs. $85.0 ; \mathrm{p}=0.01)$. 
Results of the cognitive function analyses by HIV status are shown in Table 5. Infant's HIV status was associated with gross motor scores, with the HEU infants having higher mean gross motor Tscores compared to HIV positive infants ( 50.3 vs. $40.6 ; \mathrm{p}=0.01$ ). There was no evidence of a significant difference by HIV status in the other MSEL domains and overall score.

\section{Discussion}

Our study shows a high level of stress and depressed mood scores among HIV+ve mothers. Although the EPDS scale used was not diagnostic, the general literature cut-off points indicate that $10 \%$ of mothers had scores in the severe range, while over half of the sample had scores falling in the mild to moderate range. Stress levels were also notably high.

Our study strongly suggests that higher maternal stress and depression symptoms are associated with poorer infant cognitive performance in an HIV affected sample. Maternal stress was also found to be higher in the group caring for HIV positive infants. Of note we did not find a relationship between HIV status of the infants and cognitive development - but the analysis was confined to the 16 HIV positive infants.

Contrary to findings from a Ugandan study where caregivers' depression scores were related only to the measure of child behaviour and not to the performance-based measures of cognition (Familiar et al., 2016), our results show that the expressive language and visual reception cognitive domains in particular were consistently affected by both maternal stress and depression symptoms. However, a study examining maternal depression and caregiving during the first year of life in England, suggested that maternal depression was associated with poorer caregiving of children and that the poorer caregiving was subsequently associated with poorer language development, through an indirect pathway (Stein et al., 2008). In the presence of chronic infection such as HIV, home environment and external stressors could contribute to explaining our findings of how maternal depression scores and child cognitive performance are linked. Previous studies show depression or stress among HIV positive mothers (Murphy et al., 2010) to be high when caring for HIV infected children (Murray et al., 2017) as well as being associated with negative child development outcomes (Black et al., 2007; Comaskey et al., 2017; Cummings \& Davies, 1994). It is possible that the association could be explained by both directions - the mood and stress affecting child development, or child development delays affecting maternal mood and stress.

Some of our findings were consistent with other studies which describe infants who are HIV infected experiencing an increased risk of developmental delays in the gross motor domain compared to HEU children (Hutchings \& Potterton, 2013; Knight et al., 2000; Tahan, Bruck, Burger, \& Cruz, 2006). Although available research suggests differences in the cognitive 
performances between HIV infected and HEU children (Van Rie et al., 2008; Whitehead, Potterton, \& Coovadia, 2014), we were unable to detect a difference in the overall cognitive scores between the two groups. This could be due to the very small sample size of HIV infected infants, the fact that both groups of infants lived in an HIV endemic population affected by the multifaceted ramifications of HIV, or early diagnosis and early initiation on treatment (Weber et al., 2017), as all 16 HIV positive children in this study were initiated on ART at 0 and 1 month old.

Our study had a large sample size which was representative of the study population. It also utilises assessment tools previously validated in Africa, such as the MSEL and EPDS. Nevertheless, there were a number of limitations. The cross-sectional nature of our data limited our ability to fully understand the developmental differences of the two groups over time. We were underpowered to detect a difference between HIV positive and HEU infants due to the small number of HIV positives, increasing the risk of chance effects. The Mullen scales use a US reference group which is not ideal given the setting of the study in Zimbabwe. Ideally locally validated scales and reference groups would be preferable. However the Mullen scales has been used to good effect in other studies of cognitive performance in Africa (Boivin et al., 2016; Mireku et al., 2016; RuiseñorEscudero et al., 2016) and is effective in independently measuring infants cognition rather than relying on caregiver reporting. Mental health outcome was assessed using a screening tool (EPDS) and only gave an indication of depressive symptoms rather than a clinical diagnosis of depression in mothers.

Despite the limitations, the study demonstrates the potential importance of maternal mood and stress levels in infant language and visual perception development within an HIV affected population. Introducing a comprehensive intervention, which incorporates elements of parental stress and depression reduction, as well as adequate child stimulation, may address this. Further studies exploring the drivers of maternal stress and depression symptoms could also prove to be insightful for future research.

With the roll out of $\mathrm{B}+$ strategies in pregnancy the level of HIV infection in infants will dramatically decrease. However, the group of HEU children will increase. Treatment may affect health outcomes for caregivers, but the strains of an HIV diagnosis may still be high and may influence the quality of child care and stimulation. Our data clearly indicates that mothers are recording high levels of stress and low mood and these are associated with cognitive development in young infants. Interventions to routinely identify and modify such burdens are clearly needed. These would be of benefit directly to the HIV positive mothers, and in turn may affect child development outcomes. Studies in South Africa aimed at maternal depression have shown benefits 
321 for child development (Tomlinson et al., 2015; Tomlinson, Rotheram-Borus, Scheffler, \& le Roux, 322 2017). It seems from our data that maternal factors are equally important in Zimbabwe.

323

324 Word count: 3,034

325

326 Acknowledgments

327 We would like to thank our various partners USAID-PEPFAR, the PEPFAR OVC Technical

328 Working Group, CeSHHAR, and World Education Zimbabwe (project implementing partner). We

329 would also like to thank the families and children who participated in the trial.

\section{Funding details}

331 The funding partners for the study are USAID-PEPFAR, funded under the Orphans and Vulnerable 332 Children Special Initiative.

\section{Disclosure statement}

334 The authors declare that they have no competing interests. 
Abidin, R. R. (1995). Parenting Stress Index, Third Edition: Professional Manual. Odessa, FL: Psychological Assessment Resources, Inc.

Akshoomoff, N. (2006). Use of the Mullen Scales of Early Learning for the assessment of young children with Autism Spectrum Disorders. [Research Support, N.I.H., Extramural Research Support, U.S. Gov't, Non-P.H.S.]. Child Neuropsychol, 12(4-5), 269-277. doi: 10.1080/09297040500473714

Albright, A., Soldan, S., \& Gonzalez-Scarano, F. (2003). Pathogenesis of human immunodeficiency virusinduced neurological disease. [Research Support, Non-U.S. Gov't Research Support, U.S. Gov't, P.H.S. Review]. J Neurovirol, 9(2), 222-227. doi: 10.1080/13550280390194073

Allen, A. B., Finestone, M., Eloff, I., Sipsma, H., Makin, J., Triplett, K., . . . Forsyth, B. W. (2014). The Role of Parenting in Affecting the Behavior and Adaptive Functioning of Young Children of HIV-Infected Mothers in South Africa. [journal article]. AIDS and Behavior, 18(3), 605-616. doi: 10.1007/s10461013-0544-7

Bass, J. K., Nakasujja, N., Familiar-Lopez, I., Sikorskii, A., Murray, S. M., Opoka, R., . . Boivin, M. J. (2016). Association of caregiver quality of care with neurocognitive outcomes in HIV-affected children aged 2-5 years in Uganda. [Evaluation Studies Research Support, N.I.H., Extramural]. AIDS Care, 28 Suppl 1, 76-83. doi: 10.1080/09540121.2016.1146215

Black, M. M., Baqui, A. H., Zaman, K., McNary, S. W., Le, K., Arifeen, S. E., . . Black, R. E. (2007). Depressive symptoms among rural Bangladeshi mothers: implications for infant development. J Child Psychol Psychiatry, 48(8), 764-772. doi: 10.1111/j.1469-7610.2007.01752.x

Blanchette, N., Smith, M., Fernandes-Penney, A., King, S., \& Read, S. (2001). Cognitive and Motor Development in Children with Vertically Transmitted HIV Infection.

Boivin, M. J., Nakasujja, N., Sikorskii, A., Opoka, R. O., \& Giordani, B. (2016). A Randomized Controlled Trial to Evaluate if Computerized Cognitive Rehabilitation Improves Neurocognition in Ugandan Children with HIV. Aids Research and Human Retroviruses, 32(8), 743-755. doi: 10.1089/aid.2016.0026

Chibanda, D., Mangezi, W., Tshimanga, M., Woelk, G., Rusakaniko, P., Stranix-Chibanda, L., . . Shetty, A. K. (2010). Validation of the Edinburgh Postnatal Depression Scale among women in a high HIV prevalence area in urban Zimbabwe. Arch Womens Ment Health, 13(3), 201-206. doi: 10.1007/s00737-009-0073-6

Coates, J., Swindale, A., \& Bilinsky, P. (2007). Household Food Insecurity Access Scale (HFIAS) for Measurement of Food Access: Indicator Guide (v3). Washington, DC: FHI 360/FANTA-2.

Comaskey, B., Roos, N. P., Brownell, M., Enns, M. W., Chateau, D., Ruth, C. A., \& Ekuma, O. (2017). Maternal depression and anxiety disorders (MDAD) and child development: A Manitoba population-based study. PLoS One, 12(5), e0177065. doi: 10.1371/journal.pone.0177065

Cox, J. L., Holden, J. M., \& Sagovsky, R. (1987). Detection of postnatal depression. Development of the 10item Edinburgh Postnatal Depression Scale. The British Journal of Psychiatry, 150, 782-786.

Cummings, E. M., \& Davies, P. T. (1994). Maternal depression and child development. [Review]. J Child Psychol Psychiatry, 35(1), 73-112.

Epstein, G., \& Gelbard, H. (1999). HIV-1-induced neuronal injury in the developing brain. Journal of Leukocyte Biology, 65(4), 453-457.

Familiar, I., Nakasujja, N., Bass, J., Sikorskii, A., Murray, S., Ruisenor-Escudero, H., . . Boivin, M. J. (2016). Caregivers' depressive symptoms and parent-report of child executive function among young children in Uganda. Learn Individ Differ, 46, 17-24. doi: 10.1016/j.lindif.2015.01.012

Gay, C., Armstrong, D., Cohen, D., Lai, S., Hardy, M., Swales, T., . . Scott, G. (1995). The Effects of HIV on Cognitive and Motor Development in Children Born to HIV-Seropositive Women With No Reported Drug Use: Birth to 24 Months. PEDIATRICS 96 (6).

Gibson, J., McKenzie-McHarg, K., Shakespeare, J., Price, J., \& Gray, R. (2009). A systematic review of studies validating the Edinburgh Postnatal Depression Scale in antepartum and postpartum women. Acta Psychiatr Scand, 119(5), 350-364. doi: 10.1111/j.1600-0447.2009.01363.x 
Grantham-McGregor, S., Cheung, Y. B., Cueto, S., Glewwe, P., Richter, L., \& Strupp, B. (2007). Developmental potential in the first 5 years for children in developing countries. The Lancet, 369(9555), 60-70. doi: 10.1016/S0140-6736(07)60032-4

Hutchings, J., \& Potterton, J. (2013). Developmental delay in HIV-exposed infants in Harare, Zimbabwe. Vulnerable Children and Youth Studies, 9(1), 43-55. doi: 10.1080/17450128.2013.778440

Knight, W. G., Mellins, C. A., Levenson, R. L., Jr., Arpadi, S. M., \& Kairam, R. (2000). Brief report: effects of pediatric HIV infection on mental and psychomotor development. J Pediatr Psychol, 25(8), 583-587.

Kuo, C., Cluver, L., Casale, M., \& Lane, T. (2014). Cumulative effects of HIV illness and caring for children orphaned by AIDS on anxiety symptoms among adults caring for children in HIV-endemic South Africa. AIDS Patient Care STDS, 28(6), 318-326. doi: 10.1089/apc.2013.0225

Langhaug, L. F., Cheung, Y. B., Pascoe, S., Chirawu, P., Woelk, G., Hayes, R. J., \& Cowan, F. M. (2011). How you ask the question really matters: a randomized comparison of four questionnaire delivery modes to assess validity and reliability of self-reported data on sexual behaviour in young people in rural Zimbabwe. Sexually Transmitted Infections (87), 165-173.

Le Doare, K., Bland, R., \& Newell, M. L. (2012). Neurodevelopment in children born to HIV-infected mothers by infection and treatment status. [Research Support, Non-U.S. Gov't Review]. Pediatrics, 130(5), e1326-1344. doi: 10.1542/peds.2012-0405

LeWinn, K. Z., Stroud, L. R., Molnar, B. E., Ware, J. H., Koenen, K. C., \& Buka, S. L. (2009). Elevated maternal cortisol levels during pregnancy are associated with reduced childhood IQ. International Journal of Epidemiology, 38(6), 1700-1710. doi: 10.1093/ije/dyp200

Lowick, S., Sawry, S., \& Meyers, T. (2012). Neurodevelopmental delay among HIV-infected preschool children receiving antiretroviral therapy and healthy preschool children in Soweto, South Africa. [Research Support, N.I.H., Extramural]. Psychol Health Med, 17(5), 599-610. doi: 10.1080/13548506.2011.648201

McCabe-Beane, J. E., Segre, L. S., Perkhounkova, Y., Stuart, S., \& O'Hara, M. W. (2016). The identification of severity ranges for the Edinburgh Postnatal Depression Scale. Journal of Reproductive and Infant Psychology, 34(3), 293-303. doi: 10.1080/02646838.2016.1141346

Mireku, M. O., Davidson, L. L., Boivin, M. J., Zoumenou, R., Massougbodji, A., Cot, M., \& Bodeau-Livinec, F. (2016). Prenatal Iron Deficiency, Neonatal Ferritin, and Infant Cognitive Function. Pediatrics, 138(6), e20161319. doi: 10.1542/peds.2016-1319

Mullen, E. M. (1995). Mullen scales of early learning: AGS Circle Pines, MN.

Murphy, D. A., Marelich, W. D., Armistead, L., Herbeck, D. M., \& Payne, D. L. (2010). Anxiety/stress among mothers living with HIV: effects on parenting skills and child outcomes. AIDS Care, 22(12), 14491458. doi: 10.1080/09540121.2010.487085

Murray, S. M., Familiar, I., Nakasujja, N., Winch, P. J., Gallo, J. J., Opoka, R., . . Bass, J. K. (2017). Caregiver mental health and HIV-infected child wellness: perspectives from Ugandan caregivers. AIDS Care, 29(6), 793-799. doi: 10.1080/09540121.2016.1263722

Revicki, D. A., Chan, K., \& Gevirtz, F. (1998). Discriminant validity of the Medical Outcomes Study cognitive function scale in HIV disease patients. [journal article]. Quality of Life Research, 7(6), 551-559. doi: 10.1023/a:1008866122441

Richter, L. (2004). A generation at risk? HIV/AIDS, vulnerable children and security in Southern Africa The impact of HIV/AIDS on the development of children. Pretoria: Institute for Security Studies.

Richter, L. M., Sherr, L., Adato, M., Belsey, M., Chandan, U., Desmond, C., . . Wakhweya, A. (2009). Strengthening families to support children affected by HIV and AIDS. [Review]. AIDS Care, 21 Suppl 1, 3-12. doi: 10.1080/09540120902923121

Ruiseñor-Escudero, H., Familiar-Lopez, I., Sikorskii, A., Jambulingam, N., Nakasujja, N., Opoka, R., . . Boivin, M. (2016). Nutritional and immunological correlates of memory and neurocognitive development among HIV infected children living in Kayunga, Uganda. Journal of acquired immune deficiency syndromes (1999), 71(5), 522-529. doi: 10.1097/QAI.0000000000000905

Sherr, L., Croome, N., Parra Castaneda, K., Bradshaw, K., \& Herrero Romero, R. (2014). Developmental challenges in HIV infected children-An updated systematic review. Children and Youth Services Review, 45, 74-89. doi: http://dx.doi.org/10.1016/j.childyouth.2014.03.040 
Smith, R., Chernoff, M., Williams, P. L., Malee, K. M., Sirois, P. A., Kammerer, B., . . Pediatric, H. I. V. A. C. S. T. (2012). Impact of HIV severity on cognitive and adaptive functioning during childhood and adolescence. Pediatr Infect Dis J, 31(6), 592-598. doi: 10.1097/INF.0b013e318253844b

Stein, A., Malmberg, L. E., Sylva, K., Barnes, J., Leach, P., \& team** , F. (2008). The influence of maternal depression, caregiving, and socioeconomic status in the post-natal year on children's language development. Child Care Health Dev, 34(5), 603-612. doi: 10.1111/j.1365-2214.2008.00837.x

Tahan, T. T., Bruck, I., Burger, M., \& Cruz, C. R. (2006). Neurological profile and neurodevelopment of 88 children infected with HIV and 84 seroreverter children followed from 1995 to 2002. Brazilian Journal of Infectious Diseases, 10, 322-326.

Tomlinson, M., Rotheram-Borus, M. J., Harwood, J., le Roux, I. M., O'Connor, M., \& Worthman, C. (2015). Community health workers can improve child growth of antenatally-depressed, South African mothers: a cluster randomized controlled trial. BMC Psychiatry, 15, 225. doi: 10.1186/s12888-0150606-7

Tomlinson, M., Rotheram-Borus, M. J., Scheffler, A., \& le Roux, I. (2017). Antenatal depressed mood and child cognitive and physical growth at 18-months in South Africa: a cluster randomised controlled trial of home visiting by community health workers. Epidemiol Psychiatr Sci, 1-10. doi: $10.1017 /$ s2045796017000257

UNAIDS. (2015). HIV and AIDS Estimates, 2015. http://aidsinfo.unaids.org/ Retrieved 15/3, 2017

UNAIDS. (2017). Global HIV Statistics- Fact Sheet July 2017. http://www.unaids.org/sites/default/files/media asset/UNAIDS FactSheet en.pdf Retrieved 27 August, 2017

Van Rie, A., Mupuala, A., \& Dow, A. (2008). Impact of the HIV/AIDS Epidemic on the Neurodevelopment of Preschool-Aged Children in Kinshasa, Democratic Republic of the Congo. Pediatrics, 122(1), e123e128. doi: 10.1542/peds.2007-2558

Walker, S. P., Wachs, T. D., Meeks Gardner, J., Lozoff, B., Wasserman, G. A., Pollitt, E., \& Carter, J. A. (2007). Child development: risk factors for adverse outcomes in developing countries. The Lancet, 369(9556), 145-157. doi: 10.1016/s0140-6736(07)60076-2

Weber, V., Radeloff, D., Reimers, B., Salzmann-Manrique, E., Bader, P., Schwabe, D., \& Konigs, C. (2017). Neurocognitive development in HIV-positive children is correlated with plasma viral loads in early childhood. Medicine (Baltimore), 96(23), e6867. doi: 10.1097/MD.0000000000006867

Whitehead, N., Potterton, J., \& Coovadia, A. (2014). The neurodevelopment of HIV-infected infants on HAART compared to HIV-exposed but uninfected infants. [Comparative Study]. AIDS Care, 26(4), 497-504. doi: 10.1080/09540121.2013.841828 
493 Table 1. Baseline characteristics of study sample

494 Table 2. Summary of association of maternal mental health (using EPDS) with child cognitive 495 outcomes

496 Table 3. Summary of association of maternal stress (using the PSI-SF total stress score) with child 497 cognitive outcomes

498 Table 4. Selected Infant and caregiver characteristics by HIV status

499 Table 5. Mullen T-scores of the HIV positive and HIV-exposed uninfected infants 500 
Table 1: Baseline characteristics of study sample

\begin{tabular}{|c|c|c|}
\hline Characteristics & \multicolumn{2}{|c|}{ Total Sample $(n=562)$} \\
\hline \multicolumn{3}{|l|}{ Infant } \\
\hline Age (Months), mean (SD) & 11.9 & 6.5 \\
\hline \multicolumn{3}{|l|}{ Gender, n (\%) } \\
\hline Female & 287 & 51.1 \\
\hline Male & 275 & 48.9 \\
\hline Birth weight (Kilograms) , mean (SD) & 3.0 & 0.5 \\
\hline \multicolumn{3}{|l|}{ Growth rate $\sim, \mathrm{n}(\%)$} \\
\hline Normal & 262 & 47.1 \\
\hline Moderately underweight & 273 & 49.1 \\
\hline Severely underweight & 21 & 3.8 \\
\hline \multicolumn{3}{|l|}{ Caregiver } \\
\hline Age (Years), mean (SD) & 31.5 & 6.3 \\
\hline $\begin{array}{l}\text { Education level (Completed secondary school and above), } \mathrm{n} \\
(\%)\end{array}$ & 301 & 53.6 \\
\hline \multicolumn{3}{|l|}{ Marital status $\sim^{\wedge}, \mathrm{n}(\%)$} \\
\hline Married & 447 & 79.7 \\
\hline Divorced/separated & 74 & 13.2 \\
\hline Widowed & 27 & 4.8 \\
\hline Never been married & 13 & 2.3 \\
\hline Employment status (Yes-employed), n (\%) & 206 & 36.7 \\
\hline \multicolumn{3}{|l|}{ Number of adults living in the same household ${ }^{+}, \mathrm{n}(\%)$} \\
\hline $1-3$ adults & 502 & 90.5 \\
\hline 4-6 adults & 50 & 9.0 \\
\hline $7-9$ adults & 3 & 0.5 \\
\hline \multicolumn{3}{|l|}{ Household food security, $\mathrm{n}(\%)$} \\
\hline Little to no hunger & 335 & 59.6 \\
\hline Moderate to severe hunger & 227 & 40.4 \\
\hline Maternal depression scores (EPDS), mean (range), SD & $\begin{array}{l}11.5 \\
(0-30)\end{array}$ & 6.5 \\
\hline $\begin{array}{l}\text { Maternal depression scores } \\
\text {-Severity ranges of Edinburgh Postnatal Depression Scales, } \mathrm{n}\end{array}$ & & \\
\hline
\end{tabular}




\begin{tabular}{|l|l|l|}
\hline \multicolumn{1}{|l|}{$(\%)$} & & \\
\hline None or minimal depression score & 143 & 25.4 \\
\hline Mild depression score & 190 & 33.8 \\
\hline Moderate depression score & 171 & 30.4 \\
\hline Severe depression score & 58 & 10.3 \\
\hline Maternal total stress scores (PSI-SF), mean (range), SD & $\begin{array}{l}84.8 \\
(49-149)\end{array}$ & 16.3 \\
\hline
\end{tabular}

Abbreviations: PSI-SF, Parental Stress Index-Short Form | SD, Standard Deviation

$\sim$ Missing data: Growth rate variable had 6 missing records $\mid$ Birth weight variable had 2 missing records $\mid$ marital status variable had 1 missing record

^ Marital status variable was recoded to married/not married during analysis

+There was 1 inaccurate record for the variable "Number of adults living in the same household" which was excluded from the table.

Table 2: Summary of association of maternal mental health (using EPDS) with child cognitive outcomes

\begin{tabular}{|l|l|l|c|}
\hline Mullen Scales (T-scores) & $\begin{array}{l}\text { Unadjusted mean } \\
\text { difference }(95 \% \text { CI) }\end{array}$ & $\begin{array}{l}\text { Adjusted mean } \\
\text { difference (95\% CI) }\end{array}$ & $\begin{array}{c}\text { P } \\
\text { value* }\end{array}$ \\
\hline Expressive Language & $-0.16(-0.30$ to -0.03$)$ & $-0.14(-0.27$ to -0.01$)$ & 0.04 \\
\hline Fine Motor & $-0.14(-0.28$ to -0.00$)$ & $-0.17(-0.33$ to -0.01$)$ & 0.03 \\
\hline Gross Motor & $-0.06(0.20$ to 0.07$)$ & $-0.22(-0.40$ to -0.04$)$ & 0.02 \\
\hline Receptive Language & $-0.13(-0.27$ to 0.01$)$ & $-0.15(-0.30$ to 0.01$)$ & 0.07 \\
\hline Visual Reception & $-0.14(-0.29$ to 0.01$)$ & $-0.22(-0.40$ to -0.05$)$ & 0.01 \\
\hline $\begin{array}{l}\text { Early Learning Composite } \\
\text { Score }\end{array}$ & $-0.25(-0.46$ to -0.04$)$ & $-0.28(-0.50$ to -0.06$)$ & 0.01 \\
\hline
\end{tabular}

* Regression analysis was carried out relating MSEL scales and maternal depression. The models were adjusted for tested confounders (infant age, HIV status and caregiver's employment status).

Table 3: Summary of association of maternal stress (using the PSI-SF total stress score) with child cognitive outcomes

\begin{tabular}{|l|l|l|c|}
\hline Mullen Scales (T-scores) & $\begin{array}{l}\text { Unadjusted mean } \\
\text { difference (95\% CI) }\end{array}$ & $\begin{array}{l}\text { Adjusted mean } \\
\text { difference (95\% CI) }\end{array}$ & $\begin{array}{l}\text { Palue* } \\
\text { val }\end{array}$ \\
\hline Expressive Language & $-0.12(-0.17$ to -0.07$)$ & $-0.07(-0.12$ to -0.01$)$ & 0.01 \\
\hline
\end{tabular}




\begin{tabular}{|l|l|l|c|}
\hline Fine Motor & $-0.06(-0.12$ to -0.01$)$ & $-0.02(-0.08$ to 0.05$)$ & 0.58 \\
\hline Gross Motor & $-0.08(-0.13$ to -0.02$)$ & $-0.12(-0.18$ to -0.05$)$ & $<0.01$ \\
\hline Receptive Language & $-0.09(-0.14$ to -0.03$)$ & $-0.06(-0.13$ to 0.00$)$ & 0.06 \\
\hline Visual Reception & $-0.11(-0.18$ to -0.05$)$ & $-0.09(-0.16$ to -0.02$)$ & 0.02 \\
\hline $\begin{array}{l}\text { Early Learning Composite } \\
\text { Score }\end{array}$ & $-0.19(-0.27$ to -0.10$)$ & $-0.11(-0.20$ to -0.02$)$ & 0.02 \\
\hline
\end{tabular}

* Regression analysis was carried out relating MSEL scales and maternal stress. The models were adjusted

517 for tested confounders (infant age, HIV status, growth rate, and examiner conducting the Mullen

518 assessments).

Table 4: Selected Infant and caregiver characteristics by HIV status

\begin{tabular}{|c|c|c|c|c|c|c|c|}
\hline Characteristics & \multicolumn{2}{|c|}{$\begin{array}{l}\text { HIV Positive } \\
\text { infants }(n=16)\end{array}$} & \multicolumn{2}{|c|}{$\begin{array}{l}\text { HEU infants } \\
\qquad(\mathrm{n}=\mathbf{3 8 1})\end{array}$} & \multicolumn{2}{|c|}{$\begin{array}{l}\text { Total Sample } \\
\qquad(\mathrm{n}=397)\end{array}$} & $\begin{array}{c}\mathbf{P} \\
\text { Values }\end{array}$ \\
\hline Age (Months), mean (SD) & 14.6 & 5.5 & 14.1 & 5.5 & 14.1 & 5.5 & 0.71 \\
\hline Gender, n (\%) & & & & & & & 0.71 \\
\hline Female & 9 & 56.3 & 196 & 51.4 & 205 & 51.6 & \\
\hline Male & 7 & 43.8 & 185 & 48.6 & 192 & 48.4 & \\
\hline $\begin{array}{l}\text { Birth weight (Kilograms), } \\
\text { mean (SD) }\end{array}$ & 2.8 & 0.7 & 3.0 & 0.5 & 3.0 & 0.5 & 0.19 \\
\hline \multicolumn{8}{|l|}{ Caregiver } \\
\hline Age $($ Years $) *$, mean $(\mathrm{SD})$ & 29.1 & 6.0 & 32.1 & 6.1 & 32.0 & 6.1 & 0.05 \\
\hline $\begin{array}{l}\text { Maternal depression } \\
\text { scores (EPDS), } \\
\text { mean (range), SD }\end{array}$ & $\begin{array}{l}12.2 \\
(0-30)\end{array}$ & 7.9 & $\begin{array}{l}11.6 \\
(0-30)\end{array}$ & 6.4 & $\begin{array}{l}11.6 \\
(0-30)\end{array}$ & 6.5 & 0.72 \\
\hline $\begin{array}{l}\text { Maternal total stress } \\
\text { scores }(\mathrm{PSI}-\mathrm{SF})^{*}, \text { mean } \\
\text { (range), SD }\end{array}$ & $\begin{array}{l}95.8 \\
(40-142)\end{array}$ & 22.0 & $\begin{array}{l}85.0 \\
(40-142)\end{array}$ & 15.9 & $\begin{array}{l}85.4 \\
(40-142)\end{array}$ & 16.3 & 0.01 \\
\hline
\end{tabular}

521 Abbreviations: HEU, HIV-Exposed Uninfected |PSI-SF, Parental Stress Index-Short Form | SD, Standard 522 Deviation.

$523 *$ Variables with $\mathrm{p}<0.05$ were considered to be statistically significant results. 
Table 5: Mullen T-scores of the HIV positive and HIV-exposed uninfected infants

\begin{tabular}{|l|l|l|l|l|l|l|}
\hline & \multicolumn{2}{|c|}{$\begin{array}{c}\text { HIV Positive } \\
\text { infants (n=16) }\end{array}$} & \multicolumn{2}{|c|}{$\begin{array}{c}\text { HEU infants } \\
(n=381)\end{array}$} & $\begin{array}{c}\text { Adjusted Mean } \\
\text { difference } \\
(95 \% \text { CI) }\end{array}$ & P value* \\
\hline $\begin{array}{l}\text { Mullen Scales (T- } \\
\text { scores) }\end{array}$ & Mean & SD & Mean & SD & & \\
\hline Expressive Language & 51.3 & 13.8 & 51.2 & 10.4 & $-1.92(-6.69$ to 2.83$)$ & 0.43 \\
\hline Fine Motor & 51.2 & 13.4 & 49.8 & 11.7 & $-2.27(-8.09$ to 3.54$)$ & 0.44 \\
\hline Gross Motor & 40.6 & 14.7 & 50.3 & 11.2 & $8.02(1.93$ to 14.11$)$ & 0.01 \\
\hline Receptive Language & 48.4 & 13.2 & 46.2 & 11.7 & $-0.51(-6.19$ to 5.17) & 0.86 \\
\hline Visual Reception & 50.9 & 16.0 & 52.0 & 13.1 & $1.62(-4.76$ to 8.01$)$ & 0.62 \\
\hline $\begin{array}{l}\text { Early Learning } \\
\text { Composite Score }\end{array}$ & 101.3 & 22.8 & 100.0 & 18.4 & $-1.18(-9.14$ to 6.79) & 0.77 \\
\hline
\end{tabular}
infant's age, gender, growth rate and mother's age. 